\title{
PEDRO ÁNGEL ALBISU Y LA PROCLAMACIÓN DE CARLOS IV POR EL CONSULADO DE CÁDIZ
}

\section{PEDRO ÁNGEL ALBISU AND THE PROCLAMATION OF CARLOS IV BY THE CONSULATE OF CÁDIZ}

\author{
Alfredo J. Morales \\ Universidad de Sevilla, España \\ ajmorales@us.es
}

\begin{abstract}
Con motivo de la proclamación de Carlos IV el Consulado de Cádiz, erigió un monumento efímero en la Plaza de San Juan de Dios y delante de las Puertas del Mar, que fue diseñado por el arquitecto Pedro Ángel Albisu. La estructura neoclásica se decoró con esculturas de Cosme Velázquez y Juan Gandulfo y con pinturas de Manuel de Arenas, componiendo un programa iconográfico que aludía al monarca, al propio Consulado y a América.

Palabras clave: Carlos IV, arquitectura efímera, Consulado, Cádiz, Pedro Ángel Albisu, Cosme Velázquez, Juan Gandulfo, Manuel de Arenas.
\end{abstract}

On the occasion of the proclamation of Carlos IV, the Consulate of Cádiz built an ephemeral monument at the Square of "San Juan de Dios" facing the "Gates of the Sea". It was designed by architect Pedo Ángel Albisu. The neoclassical structure was decorated with sculptures by Cosme Velázquez and Juan Gandulfo and with paintings by Manuel de Arenas, composing an iconographic programme wich alluded to de monarch, the Consulate itself and América.

Key words: Carlos IV, ephemeral architecture, Consulate, Cádiz, Pedro Ángel Albisu, Cosme Velázquez, Juan Gandulfo, Manuel de Arenas.

De las fiestas celebradas con motivo de los acontecimientos vitales de los monarcas siempre alcanzaron un singular desarrollo las relativas a su proclamación y juramento, pues además de exaltar en ellas al príncipe virtuoso y al gobernante ejemplar, se daba público testimonio de obediencia y respeto al soberano. Por eso no debe extrañar que con independencia de las que con carácter oficial y en cumplimiento de las cédulas reales recibidas debían organizar las autoridades municipales, otras instituciones quisieran también testimoniar su acatamiento y fidelidad al nuevo soberano. Como ya tuve ocasión de señalar 
en una ocasión precedente, de cuantas proclamaciones tuvieron lugar durante el siglo XVIII, fue la del rey Carlos IV una de las que mayor número de festejos propició ${ }^{1}$. De varios de los que tuvieron por escenario a diversas poblaciones andaluzas dieron cuenta Escalera Pérez y posteriormente Camacho Martínez ${ }^{2}$. A ellos se suma el que ahora doy a conocer, celebrado en Cádiz y que tiene la particularidad de no haber sido organizado por la ciudad, sino por una de sus principales instituciones mercantiles, el Consulado de Cargadores a Indias. No era la primera vez que dicha corporación de comerciantes organizaba fiestas para celebrar la proclamación de un monarca, pues como ya analicé en una ocasión precedente también lo hizo en 1759 con motivo de la subida al trono de Carlos $\mathrm{III}^{3}$. En esa ocasión procedió a erigir un "aparato" que a la manera de retablo barroco y con iconografía profana, ocultaba la fachada de la sede consular y le otorgaba la apariencia de un palacio real. Con motivo de la proclamación de Carlos IV el signo estético de la arquitectura efímera que se levantó y el propio escenario cambiaron radicalmente.

La documentación correspondiente a esta arquitectura efímera es de carácter contable, se conserva en el Archivo General de Indias y aunque en ella se alude a que estaba previsto abrir un grabado representándola, no parece que se llevara a efecto ${ }^{4}$. Así pues, no resulta posible conocer su aspecto concreto, aunque las cuentas y recibos permiten deducir algo de sus líneas compositivas generales, así como saber parte de sus motivos iconográficos y algunos de los festejos que la completaron, además de ciertos problemas que su montaje ocasionó.

Las primeras referencias al aparato festivo corresponden a la Junta General celebrada por el Consulado el 7 de marzo de 1789, cuando se decidió que sus gastos serían repartidos entre todos los comerciantes y se nombró a José de Echea, Manuel de Laraviedra, Manuel de Llera y Pedro de Palacio, como diputados

${ }^{1}$ MORALES, Alfredo J.: “Al Sol Hispano. Fiestas en Guayaquil por la exaltación al trono de Carlos IV", en ZAFRA, Rafael y AZANZA, José Javier: Emblemática trascendente. Hermenéutica de la imagen, iconología del texto. Pamplona, 2011, p. 542.

2 ESCALERA PÉREZ, Reyes: La imagen de la sociedad barroca andaluza. Estudio simbólico de la decoración efimera en la fiesta altoandaluza. Siglos XVII y XVIII. Málaga, 1994. CAMACHO MARTÍNEZ Rosario: "Fiestas por la proclamación de Carlos IV en algunas ciudades andaluzas", en TORRIONE, Margarita (Ed.). España festejante. El siglo XVIII. Málaga, 2000, pp. 495-504.

${ }^{3}$ MORALES, Alfredo J.: "El Consulado de Cádiz y la proclamación de Carlos III", en IV Jornadas de Arte. El Arte en Tiempo de Carlos III. Madrid, 1989, pp. 160-166.

${ }^{4}$ Archivo General de Indias (A.G.I.). Consulados, 91, nº 4 Documentos sobre la jura de Carlos IV y cuenta de gastos de construcción de un monumento para su celebración. El título es moderno. El expediente incluye la cuenta general de gastos, más un conjunto de recibos y papeles sin ordenar y sin foliación, aunque algunos aparecen encabezados por letras mayúsculas. 
responsables de llevarlo a cabo ${ }^{5}$. Con gran rapidez acometieron el encargo, pues el día 16 se dirigían al Prior y a los Cónsules de dicho organismo indicando que también los comerciantes de Jerez de la Frontera y El Puerto de Santa María debían participar de la derrama, convencidos de que todos estarían dispuestos a colaborar en la celebración. Sin embargo, como después comprobarían, serían varios los que finalmente se negarían a participar en los gastos ${ }^{6}$.

Casi de inmediato se debieron poner en contacto con el arquitecto municipal Pedro Ángel Albisu, a fin de solicitarle el correspondiente proyecto arquitectónico, pues el último día del mes el maestro de carpintería Vicente Millán firmaba la carta de obligación para construir el monumento efímero, conforme al dibujo y las condiciones elaboradas por dicho arquitecto. De acuerdo con ellas se comprometía a levantar la estructura de dos cuerpos y después a desmontarla, recibiendo por ello 2.700 pesos, cantidad en la que se incluían la madera, los clavos y los jornales de los trabajadores. Dicha cantidad se fraccionaría en tres pagos, renunciando a cualquier otra posterior petición económica ${ }^{7}$. No eran de su responsabilidad las esculturas y la pintura del aparato, aunque sí tendría que preparar las diferentes piezas para poder pintarlas con posterioridad. Tendría que colocar la estructura delante de las Puertas del Mar, dando frente a la Plaza de San Juan de Dios y conforme al dibujo que le facilitara el arquitecto, para el día 15 de mayo o poco después, según fijase el Ayuntamiento de la ciudad la fecha en la que tendría lugar la jura del nuevo monarca ${ }^{8}$. Señalaba que aunque en el dibujo de Albisu se incorporaban unas estatuas sobre la balaustrada y las bóvedas, deberían reemplazarse por jarrones que diseñaría el propio arquitecto, quien también señalaría

5 José de Echea era natural de Cádiz y su matrícula en el Consulado data de 1748. Manuel de Laraviedra, natural de Llano en la provincia de Burgos, se incorporó a dicho organismo en 1777. Manuel de Llera, que era natural de Ajamil, en La Rioja, realizó su ingreso en el Consulado en 1786. Por su parte Pedro de Palacio, natural de San Martín, en Vizcaya, accedió al Consulado en 1770. Véase RUIZ RIVERA, Julián B.: El Consulado de Cádiz. Matrícula de Comerciantes. 1730-1823. Cádiz, 1988, pp. 155, 174, 178 y 190 , respectivamente.

${ }^{6}$ Así lo expresan los diputados Echea, Laraviedra y Palacio en una carta dirigida al Prior y Cónsules, fechada el 12 de octubre del mismo año.

${ }^{7}$ Sin embargo, Vicente Millán, recibió el primer pago de 900 pesos el día 3 de abril, el segundo por idéntica cantidad el día 18 del mismo, dos pagos intermedios por 4.000 reales los días 11 y 19 de mayo y el pago final de 5.500 reales el día 29 de este mes. El primero de ellos lo recibió de don Manuel de Laraviedra, el segundo de don Manuel de Llera y los restantes de don Pedro de Palacio, quienes eran diputados de la obra. Como se verá, recibió otros pagos, si bien corresponden a una ampliación de la estructura y la incorporación de un jardín delante de la decoración. El propio Millán sirvió de intermediario para pagar a los mozos que durante los tres días y tres noches en que se celebró la jura vigilaron la arquitectura y su iluminación.

${ }^{8}$ Las citadas puertas fueron derribadas en 1906. 
el grosor de los balaustres ${ }^{9}$. Finaliza el documento señalando que levantaría la estructura sólida y segura y que cualquier aspecto no recogido en el dibujo y que se incorporara por criterio del citado arquitecto, tendría que asumirlo como parte del contrato, sin exigir nada más a cambio.

El día 24 de abril el pintor Manuel de Arenas, tras conocer el proyecto de Albisu y ver la arquitectura que ejecutaban los carpinteros en unos dormitorios y el corralón del convento de San Francisco, se comprometía a pintarla por 1.850 pe$\operatorname{sos}^{10}$. Según las condiciones establecidas los diferentes elementos arquitectónicos deberían ir pintados y barnizados imitando mármoles blancos o jaspes verdes, o del color que mejor pareciera al arquitecto, mientras las pilastras, capiteles y perfiles de los arcos se pintarían simulando ser de bronce. El espacio central llevaría pavimento a color y veteado lo correspondiente a los jaspes, mientras el de las galerías serían losas y las escaleras de color blanco. En el techo de la citada galería se deberían pintar al temple unos recuadros con trofeos, mientras en las interpilastras de la fachada que miraba a la muralla se pintarían jeroglíficos del comercio o de navíos o de otras temáticas. En el segundo cuerpo irían pintadas ochos figuras que presentarían a la abundancia, la felicidad, la paz, la agricultura, el comercio, la esperanza, la justicia y la astronomía. En los intercolumnios se debían pintar con sus nombres para que pudieran reconocerse Cristóbal Colón, Juan Sebastián Elcano, Hernán Cortés, Pedro de Alvarado, Gonzalo de Sandoval, Andrés de Tapia, Pedro Fernández de Lugo, Francisco Pizarro, Fernando de Magallanes y Américo Vespucio ${ }^{11}$. En el segundo cuerpo debería pintar en jaspe blanco veteado una cartela, en la que pondría en letras mayúsculas la inscripción que se le ordenase. También procedería según se le indicase en relación con los jarrones del coronamiento y los trofeos de los remates. Una vez colocada toda la arquitectura en su emplazamiento debería repasar y retocar las juntas o los golpes que las piezas

${ }^{9}$ Por la información que posteriormente se aporta resulta evidente que finalmente sí se colocaron esculturas sobre las bóvedas y la balaustrada

${ }^{10} \mathrm{El}$ procurador mayor del convento, fray Alonso Prieto, recibió el 26 de junio 60 pesos en concepto de limosna por haber utilizado durante dos meses como taller de los carpinteros las aludidas dependencias conventuales.

${ }^{11}$ El texto solo incluye los apellidos de los distintos personajes, por lo que en el caso de los simplemente denominados como Tapia y Lugo, sospecho que corresponden a los dos personajes indicados. Andrés de Tapia participó con Cortés en la conquista de México y fue autor de una famosa Relación sobre los hechos del propio Cortés que sirvió de base a la crónica de Francisco López de Gómara y posiblemente a la de Bernal Díaz del Castillo. Por su parte Pedro Fernández de Lugo, segundo Adelantado de Canarias y gobernador de Tenerife y La Palma, emprendió una expedición para la conquista de Santa Marta, en nueva Granada, de la que fue gobernador. También su hijo Alonso Luis de Lugo ocupó la misma gobernación, pero no creo que se aluda a él, pues su labor colonizadora tuvo menos repercusión, aunque se le considera conquistador del valle de Ibagué y fundador de la ciudad de Tocaima. 
pudieran haber sufrido durante el traslado o su instalación. Aunque en este documento no se alude a ello, consta en otro que también le correspondió dorar las cuerdas de las que se colgaron las arañas que iluminaban la arquitectura ${ }^{12}$. Todo el trabajo tendría que hacerlo de acuerdo con las instrucciones de Albisu y estar terminado hacia fines de mayo, en función de la fecha elegida por la ciudad para colocar sus decoraciones y celebrar la proclamación del rey.

Seis días después de la fecha de este contrato el maestro escultor Juan Gandulfo firmaba el correspondiente a la hechura de dos figuras de la fama de casi 1'70 metros de altura, que deberían ir situadas sobre las cúpulas ${ }^{13}$. Se trataba de esculturas que solo tendrían de madera la cabeza, brazos y pies, fabricándose el resto del cuerpo con lienzo encolado. Ambas llevarían su clarín y mientras una portaría la corona de laurel, la otra llevaría un cetro. Debía concluirlas para el 19 o 20 de mayo y recibiría por ellas un total de 180 pesos. Dicha cantidad la percibió en dos pagos los días 2 y 26 de mayo, cobrando el 20 de junio 6.000 reales por dos esferas que debieron servir de pedestales a las figuras y por los hierros que les dieron estabilidad ${ }^{14}$. Tales elementos no estaban contemplados en el contrato inicial.

No fueron estas las únicas esculturas que aparecieron en la decoración, pues consta por algunos recibos relativos a su pintura que sobre la balaustrada se ubicaron un total de treinta y seis representando las cuatro partes del mundo, existiendo además los escudos real y del Consulado y otras cuatro esculturas en las dos fuentes. Sin embargo, ninguno de los recibos y cuentas del expediente indican su autor, aunque consta que su pintura corrió a cargo de Juan González de Herrera $^{15}$. Sí se sabe que la escultura ecuestre del rey que remató la decoración se le encomendó, sin duda por su reconocido prestigio, a Cosme Velázquez, quien era director de escultura de la recién creada Escuela de Nobles Artes. Su trabajo se evaluó en 11.000 reales y es muy posible que la mencionada figura se realizara

${ }^{12}$ Dicho cordel fue suministrado por Miguel Martínez, pagándosele el 6 de junio 762 reales.

${ }^{13}$ A este escultor gaditano de familia genovesa se le ha atribuido tradicionalmente la imagen del Crucificado que integra el grupo del Calvario existente en la cripta del oratorio de la Santa Cueva de la capital gaditana. Así se recoge por Paolocci, quien además de referencias familiares ofrece una relación de las obras atribuidas. Véase PAOLOCCI, Claudio (dir.): Scultura lignea genovese a Cadice del Settecento. Opere e Documenti. Génova, 1993, pp. 71-76. Sin embargo, en fecha más reciente, Sánchez Peña, tras documentar obras suyas en la Iglesia Mayor de San Fernando, considera que fue autor de todo este grupo que representa las Siete Palabras y también del Cristo a la columna del mismo oratorio. Véase SÁNCHEZ PEÑA, José Miguel: Escultura genovesa. Artífices del Setecientos en Cádiz. Cádiz, 2006, pp. 1712-182.

${ }^{14}$ El primero de los pagos lo efectuó don Manuel de Llera, quien el 23 de mayo escribió al también diputado, don Pedro de Palacio, para que le entregase al escultor los 1.600 reales que restaban del total y los anotase en la relación de gastos.

${ }^{15}$ El 17 de junio cobró 1.980 reales, después de rebajar 360 reales. 
en yeso, pues una vez desmontada la decoración tuvo que ser trasladada al patio del Consulado para proceder a su destrucción ${ }^{16}$. Desde luego no sería la única ocasión en que el artista recurriría al yeso para imitar obras de mármol, siendo prueba de ello sus creaciones para el citado oratorio de la Santa Cueva ${ }^{17}$.

Cuando la mayor parte de los trabajos de la decoración efímera estaban en curso se decidió ampliarla y disponer delante de ella un jardín con fuentes. No es posible conocer en qué consistió la ampliación, pero debió estar relacionada con la presencia de esculturas sobre las balaustradas y las dos cúpulas laterales. Como se indicó, tales figuras aparecían en el proyecto inicial de Albisu, pero en el momento de contratar la arquitectura con el maestro carpintero se decidió reemplazarlas por jarrones ${ }^{18}$. Las razones por las que se volvió a la idea primitiva se ignoran, aunque cabe sospechar que se advertiría el escaso contenido simbólico que ofrecería el aparato efímero si se prescindía de esas figuras. Además debió tenerse en cuenta que con su presencia el monumento ganaría en esbeltez y que podría en parte contrarrestarse el protagonismo de la trasera del frontón y de los jarrones que le servían de acróteras a las Puertas del Mar, en cuyo diseño había tenido un destacado papel el ingeniero Ignacio Sala.

También se contó con el citado maestro carpintero Vicente Millán para realizar los cambios en la arquitectura, recibiendo por su trabajo 600 pesos, la mitad de los cuales fueron de gratificación, lo que es prueba de haber cumplido a plena satisfacción con un trabajo que además de trazar Albisu, también había tasado a la baja ${ }^{19}$. Por la realización del jardín, sin duda diseñado por el mismo arquitecto, percibió 5.000 reales el día 6 de junio. La creación de este último supuso un

${ }^{16}$ El pago consta en dos recibos de fecha 30 de abril y 17 de junio. Para más información sobre este artista puede consultarse PARDO CANALIS, Enrique: Escultores del siglo XIX. Madrid, 1951, pp. 10-16 y MELENDRERAS GIMENO, José Luis: "Cosme Velázquez, director de escultura en la Escuela de Bellas Artes de Cádiz”, Gades, n¹1, 1983, p. 250. Así mismo, BANDA Y VARGAS, Antonio de la: "Evocación del escultor Cosme Velázquez en el CL aniversario de su muerte". Anales de la Academia de Bellas Artes de Cádiz, $\mathrm{n}^{\circ} 6,1988$, pp. 87-88. El traslado y la destrucción de la escultura fue realizada por Juan Vázquez, cobrando por ello 95 reales el 26 de junio.

17 Véase al respecto ALONSO DE LA SIERRA FERNÁNDEZ, Juan y Alonso: "Trabajos en yeso de Cosme Velázquez para el Oratorio de la Santa Cueva". PH Boletín del Instituto Andaluz del Patrimonio Histórico, no 33, 2000, pp. 76-86.

${ }^{18}$ En una de las cláusulas del contrato se dice textualmente "Que es aclaracion que aunque el dibujo presenta coronacion de estatuas sobre la balaustrada, y las dos medias naranjas deveran ser Jarrones del dibujo del Architecto....".

${ }_{19}$ Dicha cantidad le fue pagada el 25 de junio por el diputado don Manuel de Laraviedra. El maestro se comprometió a devolver a los diputados de la obra los recipientes, candilejas, barriles y restantes elementos del montaje efímero que no se hubieran vendido con posterioridad a la celebración, o la cantidad correspondiente si se había procedido a su venta. 
incremento de los gastos, pues fue necesario construir las fuentes con saltadores y las pertinentes conducciones, traer una bota de vino para que en algunos momentos de la celebración manara de una de las fuentes, así como más de un millar de barriles con agua para la otra, además de numerosas macetas con plantas para componerlo ${ }^{20}$. A todo ello hay que sumar el costo del alquiler de las arañas y pebeteros a la compañía Hiecke Zincke, el de los faroles, candilejas, palmatorias, jarros, alcuzas y embudos suministrados por el farolero Marcos Quijada, el valor de los pellejos de aceite que entregó Manuel Sanz y el de la cera para la iluminación que facilitaron José Reguera y Alonso Pérez. Otros gastos fueron los correspondientes a los trajes que se confeccionaron para los quince pobres que asistieron y sirvieron durante los días de la celebración y el de los mozos que vigilaron la decoración, transportaron bancos, atendieron las candilejas, cuidaron la iluminación y sirvieron de recaderos ${ }^{21}$. También se incorporaron a las cuentas las limosnas entregadas a personas necesitadas y el costo de la impresión de los recibos presentados a los comerciantes para pagar el costo del aparato y los festejos ${ }^{22}$. A este respecto y como ya se anticipó, hubo varios que se negaron a contribuir, argumentando las más variadas razones ${ }^{23}$. Ante tal situación los diputados efectuaron todo tipo de averiguaciones para desmontar sus argumentos, logrando que algunos se avinieran a colaborar. Otros por el contrario rechazaron participar, por lo que los diputados Palacio, Echea y Laraviedra escribieron el 12 de octubre al Prior y Cónsules, instándoles a que hicieran valer su autoridad y les obligasen a contribuir, para así poder recuperar las cantidades que habían adelantado.

Las cuentas presentadas por los citados diputados ponen de manifiesto que tras la arquitectura y decoración del aparato efímero, las mayores cantidades correspondieron a los diversos conciertos que amenizaron las veladas. Los de marchas militares, dirigidos por Miguel Laburier, que se celebraron durante las tres noches y la tarde en que tuvieron lugar los actos de la jura fueron interpretados por una banda de "Músicos de Cantabria" integrada por dieciocho músicos y su

${ }^{20}$ Los saltadores y las cañerías de hoja de lata de las fuentes los suministró Vicente Battallini, mientras que para las conducciones se fue al arsenal de La Carraca para obtener una manguera, que se completó con unas piezas de lona compradas a Juan Pedro Orrendi, posteriormente cosidas, embreadas y ensebadas por Francisco Trillo. La bota de vino tinto de 50 arrobas la sirvió Miguel Fernández Terán, Simón Gutiérrez entregó una tina grande con arcos de hierro y el carpintero Juan Vázquez doce botas catalanas vacías, todo destinado a la fuente. Para una de ellas se trajeron desde Puerta de Tierra por Juan Freire y Leonardo Grafouliera un total de 1.459 barriles de agua, trasladando desde el mismo lugar Ignacio García las macetas con plantas que simularon el jardín.

${ }^{21}$ Los trajes fueron realizados por Manuel Mañón, las medias las suministró Ventura Pujades y otros géneros los facilitó Lacosta Casenave.

${ }^{22}$ Consta la impresión de 650 recibos de libramientos realizada por Juan Jiménez Carreño.

${ }^{23}$ Inicialmente fueron 67 los comerciantes que rechazaron colaborar. 
costo fue de 400 pesos. Por su parte, los de música de cuerda que se dieron solo en las tres noches e interpretó una orquesta dirigida por el maestro Vittorio Finarelli y que estuvo integrada por veintiocho profesores nacionales y extranjeros costó $897 \operatorname{pesos}^{24}$. Algo más elevada, 900 pesos, fue la cantidad que percibió Pedro Ángel Albisu por el diseño y dirección de los trabajos y por su compromiso de entregar "acabado el plan de dicha obra con su jardín, para mandar al grabador que hade abrir la lamina por mi dirección en Madrid". Ésta debió ser la idea inicial, pero no parece que se llevara a cabo, pues no se ha podido localizar ninguna estampa sobre dicha decoración. Esto nos ha privado de conocer el aspecto de la arquitectura efímera que con el diseño de Albisu y bajo su dirección se erigió por el Consulado con motivo de la jura del nuevo monarca Carlos IV.

El ya aludido carácter contable de la documentación que se da a conocer tampoco facilita una descripción precisa de dicho aparato. Aun así es evidente que se trataba de una estructura de estética neoclásica, como indican las referencias a columnas y elementos de mármol y jaspe simulados. No podría ser de otra manera en un arquitecto formado en la Real Academia de Bellas Artes de San Fernando, que en 1780 había obtenido el título de académico supernumerario y que además de arquitecto municipal era a la sazón director de la sección de arquitectura de la Academia de Nobles Artes de Cádiz ${ }^{25}$. En toda su fecunda actividad, que superó los límites de la provincia gaditana y que incorporó obras de arquitectura, de ingeniería y el diseño de retablos, siempre se manifestó como un decidido difusor de la estética neoclásica ${ }^{26}$. En el caso de la arquitectura erigida para el Consulado, lo primero que llama la atención es su emplazamiento delante de las Puertas del Mar y con frente a la Plaza de San Juan de Dios, pues cuando dicha institución se sumó a los festejos por la proclamación del anterior soberano se limitó a decorar la fachada de su sede y no buscó un lugar tan privilegiado ${ }^{27}$. La nueva ubicación le sirvió al Consulado de propaganda de su papel benéfico para la vida de la ciudad, a la vez que le otorgaba a su edificio efímero un mayor protagonismo, permitiéndole entrar en competencia o servir de complemento a las decoraciones de la proclamación real construidas por el propio Albisu para el

${ }^{24}$ De dicha cantidad 10 pesos correspondieron a las copias de las partituras. En el recibo firmado por Finarelli figuran los nombres de los integrantes de la orquesta y la cantidad que cada uno percibió.

${ }^{25}$ Sobre este arquitecto puede verse FALCÓN MÁRQUEZ, Teodoro: "Biografía de Pedro Ángel Albisu”, en Homenaje al Profesor Carriazo. Sevilla, 1972, T. II, pp. 181-194. Del mismo autor Torcuato Benjumeda y la arquitectura neoclásica en Cádiz. Cádiz, 1974, pp. 48-50. Sobre la Academia y el nombramiento de Albisu puede consultarse GASCÓN HEREDIA, María Teresa: Estudio histórico de la Escuela de Nobles Artes de Cádiz: 17891842. Cádiz, 1989, p. 41.

${ }^{26} \mathrm{Su}$ aportación al retablo gaditano es estudiada por ALONSO DE LA SIERRA FERNÁNDEZ, Alonso: El retablo neoclásico en Cádiz. Cádiz, 1989, pp. 101-109.

${ }^{27}$ Véase nota $\mathrm{n}^{\circ} 3$. 
Ayuntamiento gaditano, situado frente a dichas puertas ${ }^{28}$. Es más, la obra financiada por el Consulado se programó en relación con los festejos organizados por la ciudad, de ahí la disparidad de fechas que los documentos señalan respecto a la finalización de los distintos elementos constructivos y decorativos de la "prespectiba", en función de los días que el Ayuntamiento determinara para celebrar la jura del nuevo rey.

Aunque no se indica el lugar preciso de colocación de la arquitectura del Consulado, resulta evidente que debió levantarse entre los dos arcos que constituían las traseras de las Puertas del Mar. No obstante tratarse de una estructura exenta, algún elemento debió apoyar o ser arriostrado sobre los pretiles de remate de las bóvedas dispuestas sobre los tránsitos, pues con el montaje y desmontaje se produjeron daños de cierta consideración que debieron ser reparados con posterioridad. Estos trabajos costaron 2.312 reales y 33 maravedís, fueron dirigidos por el ingeniero director de la fortificación de la ciudad Luis Huet y realizado por los maestros y oficiales responsables de la misma, entre los que figuraba José Beltrán, perceptor de la cantidad antes señalada, de la que firmó recibo el 10 de marzo de $1790^{29}$.

Como se indicaba, el aparato erigido por el Consulado se ubicaría entre los dos accesos de las Puertas del Mar, en donde existían otros dos módulos de similares proporciones a los de dichos tránsitos. Se aprovecharía pues el punto intermedio para levantar la estructura de dos cuerpos que serviría de centro a una composición prolongada en dos alas o galerías laterales extendidas hasta las proximidades de las puertas, pero sin llegar a obstaculizar un paso tan frecuentado y esencial en la vida cotidiana de la ciudad. Dicha estructura debió elevarse sobre una plataforma a la que se accedía mediante escalinatas. Tendría planta cuadrada, presentando un primer cuerpo con arcos apeados en columnas, con sus correspondientes retropilastras. Sobre el entablamento, donde posiblemente se situasen en un frente y otro el escudo real y el del Consulado, se dispondría una balaustrada entre pedestales coronados por jarrones. Seguía el segundo cuerpo,

${ }^{28}$ La autoría de Albisu se comprueba en el rechazo a una reclamación de 4.000 reales presentada por el hijo del arquitecto al Ayuntamiento el 31 de enero de 1821. En el cabildo del 8 de febrero se indicó que en la cuenta de gastos correspondiente a la proclamación de Carlos IV figuraba como pagada dicha cantidad correspondiente al trabajo del arquitecto en los diseños y la dirección de lo proyectado en las Casas Capitulares y en la plaza, llamada entonces de la Constitución, ahora de San Juan de Dios. Los documentos los recoge FALCÓN MÁRQUEZ, Teodoro: "Biografía de.... op. cit., p. 193.

${ }^{29}$ El citado ingeniero había desarrollado una amplia actividad en Ceuta y norte de África entre 1751 y 1774, pasó a América y trabajo especialmente en las defensas de Cuba. Desde 1786 se le documenta en Cádiz, apareciendo al año siguiente como brigadier e ingeniero director de las fortificaciones de la ciudad. Véase CAPEL, Horacio et alii: Los ingenieros militares en España. Siglo XVIII. Repertorio biográfico e inventario de su labor cientifica y espacial. Barcelona, 1983, pp. 231-233. 
en el que se pintarían, dos por cada frente, las virtudes y alegorías ya mencionadas. Una cartela con inscripciones se situaría en la fachada delantera. Coronaría la estructura una cubierta, posiblemente abovedada, sobre la que se situaría la escultura ecuestre de Carlos IV, realizada por Cosme Velázquez. Enlazando con el primer cuerpo, pero con menor altura, se dispondría una galería de columnas con cinco módulos por lado, ocupando los intercolumnios del frente hacia la plaza las representaciones de los conquistadores ya reseñados, mientras en la trasera se pintarían los jeroglíficos aludidos. Dichas galerías, en cuyos techos casetonados irían pinturas de trofeos, se rematarían por balaustradas sobre las que aparecerían las representaciones de las cuatro partes del mundo. Al centro de cada galería se levantaría una cúpula rematada por una de las esculturas de la fama realizadas por Juan Gandulfo. De distintos puntos colgarían las arañas y por cornisas, balaustradas, pedestales y escalones se distribuirían las candilejas, palmatorias y faroles que durante la noche iluminarían, con evidente efecto teatral, la arquitectura efímera. La precedería un jardín organizado mediante la artística agrupación de plantas y en el que destacaban las dos fuentes con esculturas de iconografía desconocida, que seguramente irían situadas delante de las galerías laterales, a eje con el ámbito cupulado. De una de aquellas manaría para el disfrute de los gaditanos y durante los días de la celebración de la jura, el vino tinto que había suministrado Miguel Fernández Terán.

Toda esta descripción no deja de ser una hipótesis de restitución, a falta de una imagen fidedigna del diseño de Albisu. También se carece de información textual sobre las imágenes, jeroglíficos e inscripciones que componían su programa iconográfico. A pesar de ello y con las limitadas referencias que los documentos aportan, pueden resaltarse algunos aspectos del mismo, en los que se combinaron alusiones al rey Carlos IV, al Consulado y a América. El hecho de recurrir a representaciones de algunos de los más importantes descubridores y conquistadores españoles en América es perfectamente explicable en una obra encargada y financiada por el Consulado y más concretamente por los mercaderes que lo integraban, pues su prosperidad y la de toda la ciudad se basaba en el comercio americano. Al respecto cabe señalar que algunos de los personajes representados, como Colón, Cortés y Pizarro, estuvieron también presentes en la decoración erigida por la misma institución con ocasión de la subida al trono de Carlos III. También en ella se recurrió a un numeroso conjunto de jeroglíficos, cuya presencia parece haber sido más limitada en la arquitectura trazada por Albisu para la de Carlos IV. Solo se indica que serían sobre temas del comercio, de navíos o de "otras alusiones" y que se dispondrían en la fachada trasera. De haberse tratado de representaciones de naves es evidente que su modelo estaría en las atracadas en los muelles, cuyas impresionantes arboladuras se podrían contemplar por encima de la muralla. La presencia de esos personajes hacía presente a los espectadores sus hazañas y victorias, como anticipo de las que alcanzaría el nuevo soberano no solo en América, sobre la que ya reinaba, sino sobre las cuatro partes del mundo, 
que aparecían sobre la balaustrada. Las representaciones del segundo cuerpo correspondientes a virtudes y alegorías estaban estrechamente relacionadas con la triunfal imagen ecuestre del monarca que coronaba la estructura. Aquellas serían las que confiaban en que ejercitase durante su justo y pacífico gobierno para conseguir el progreso del comercio, de la ciencia y de la agricultura, lo que además de resultar beneficioso para el propio Consulado, traería la felicidad a toda la población. Los logros y éxitos del soberano serían propagados por los clarines de las Famas, quienes le harían entrega del cetro del poder y de la corona de la victoria.

Tales elementos, sumados a los erigidos por el Ayuntamiento y a los que seguramente levantaron otras instituciones e incluso órdenes religiosas transformaron temporalmente la imagen cotidiana de Cádiz y además de servir para demostrar el acatamiento y fidelidad al nuevo rey, fueron ocasión de regocijo para el gentío de gaditanos que acudió a contemplar con asombro las decoraciones efímeras, a disfrutar de los conciertos y espectáculos, a gozar del vino, a dejarse llevar de la fantasía y lo maravilloso, logrando así olvidar momentáneamente la monótono y a veces penosa realidad cotidiana.

Fecha de recepción: 30 de septiembre de 2014

Fecha de aceptación: 28 de noviembre de 2014 